the Society met in Chicago to hear Professor Bôcher's presidential address. In 1913 the Council of the Society took official notice of the growing importance of the meetings of the Chicago Section by resolving that "the meetings of the Chicago group are henceforth to be designated as meetings of the Society." From 1911 on the retiring chairman delivered an address. When voting in 1913 to make the chairman's address a permanent feature, the Section expressed the opinion "that there are too few papers giving a general survey of any field of mathematics." For a short period, time was set aside on each program for "informal notes and queries" in the hope that in that way more general participation in the discussion might be secured. These different efforts to give the meetings a broader scope led, in 1915, to a proposal by Professor Van Vleck that a symposium be arranged on some topic of wide interest. But it was not until 1917 that the proposal was carried into effect; at that time Professors Bliss and Hildebrandt gave lectures on the Lebesgue Integral. From that time on a symposium address has been given at the April meeting of each year.

ARNold Dresden, Secretary of the Chicago Section.

\title{
ELIAKIM HASTINGS MOORE FUND
}

BY ARNOLD DRESDENN

A group of former students of Professor E. H. Moore, wishing to use the opportunity afforded by the twenty-fifth anniversary meeting of the Chicago Section to present to Professor Moore a testimonial of their respect and appreciation, brought together a fund to be used for furthering mathematical interest in this country. This fund was contributed to by one hundred and seventy-four persons, former graduate students of mathematics at the University of Chicago, or members of the American Mathematical Society definitely identified with its Chicago Section. On the evening of April 14, 1922, a beautifully bound and illuminated manuscript 
containing a statement of the establishment of the Eliakim Hastings Moore Fund was presented to Professor Moore. The names of the contributors to the fund are preceded by the following statement:

"Conscious of the great influence which you have exercised upon the development of mathematical science throughout this country, particularly in the Middle West, during the last twenty-five years,

Admiring the outstanding qualities of your researches in various fields of mathematics,

Grateful for the inspiration and the encouragement which you have given to those who have come to the University of Chicago to study mathematics,

Recognizing the large contribution which you have made to the creation and the growth of the Chicago Section of the American Mathematical Society,

Deeply appreciative of the friendship which, during many years, you have shown toward those who have had the good fortune to know you,

The undersigned members of the American Mathematical Society, formerly students of mathematics at the University of Chicago, or members of long standing in the Chicago Section, have wished to use the opportunity afforded by the twenty-fifth anniversary meeting of the Chicago Section to present to you a testimonial, which is intended to link your name in the years to come with the development of mathematics in this country.

To this end they have contributed to a fund which is to be offered for trusteeship to the American Mathematical Society upon the following conditions:

1. The fund is to be known as the Eliakim Hastings Moore Fund.

2. The interest on the fund is to be used at the discretion of the Council of the Society, and upon the recommendation of a committee appointed from time to time for this purpose, in furtherance of such mathematical interests as 
(a) The publication of important mathematical books and memoirs;

(b) The award of prizes for important contributions to mathematics;

it being further recommended that during the next ten years preference be given to the former, and that publication of Professor E. H. Moore's researches in General Analysis or other fields shall have precedence over all other claims.

3. The fund is to be kept intact by the American Mathematical Society, except in so far as it is used to aid in the publication of Professor Moore's researches. For this special purpose a part of the principal, not exceeding one third, may be used provided the interest on the remainder be allowed to accumulate until the fund has been restored to its original value."

At its meeting on April 15, the Council of the Society accepted the trusteeship of this fund as recorded elsewhere in the BULLETIN.

It is hoped that the Eliakim Hastings Mocre Fund, which has now reached approximately $\$ 2,000$, may be the nucleus of a much larger fund to be ultimately established and to be at the disposal of the American Mathematical Society for aid in the publication of important mathematical work. The fund will remain open for contributions at any time, and it is hoped that those who are interested and who had no opportunity to join in the testimonial at the time of its foundation may do so later. Contributions may be sent to the Secretary of the Society, Professor R. G. D. Richardson, Brown University, Providence, Rhode Island.

The University of Wisconsin. 